\title{
Understanding pastoral mobility: the case of Senegalese Fulani
}

\author{
HANNE KIRSTINE ADRIANSEN \\ Danish Institute for International Studies, Strandgade 56, DK-1401 Copenhagen K, Denmark \\ E-mail: hka@diis.dk \\ This paper was accepted for publication in February 2008
}

\begin{abstract}
Based on a case study from Sahelian Senegal, this paper analyses how various actors perceive the importance of pastoral mobility and presents issues of importance for understanding the use of mobility among Fulani of Ferlo. One knowledge system is a scientific one, the 'new rangeland paradigm'. According to this, pastoral mobility is a means to balance variability in dryland resources; hence, 'nature' is the point of departure. Another knowledge system is local pastoral knowledge. For the pastoralists, the well-being of their animals is the point of departure and mobility is used to ensure that the livestock are in good condition. The paper shows that it is important to distinguish between mobility of pastoralists and of their herd; even though the pastoralists of northern Senegal have become semi-sedentary, their herds are still quite mobile. The pastoralists are willing to move around within a small territory, which they consider their place, but are unwilling to employ large-scale mobility themselves. Mobility is not of importance for their ethnic identity and some use paid herders to care for their livestock. By looking at both knowledge systems, we achieve a better understanding of pastoral mobility and how this may change in the future.
\end{abstract}

KEY WORDS: Senegal, pastoral mobility, Fulani, knowledge systems, rangeland ecology

\section{Introduction}

I $\mathrm{n}$ the debate concerning land degradation, desertification, and pastoral production, the 'new rangeland paradigm' brought new insights into dryland functioning in the early 1990s. ${ }^{1}$ Within this paradigm, pastoral mobility is perceived as ecologically rational in an environment characterised by high variability of natural resources (Niamir-Fuller 1998; Thébaud and Batterbury 2001). Recently, it has become in vogue to combine scientific environmental knowledge with so-called local or indigenous knowledge using different methods and data sources (e.g. Bollig and Schulte 1999; Eriksen 2007; Oba and Kotile 2001). Yet, as noted by Thomas and Twyman (2004, 215), 'scientific and local land-user views of change do not always tally, leading to conflicts in aid agendas and policy recommendation'. Some of these differences can be explained by differences in scale, i.e. local populations often operate at a smaller scale than scientists, especially in studies using satellite imagery and aerial photos (Campbell et al. 2005; Nielsen and Adriansen 2005). The lack of agreement between scientific and local knowledges can also be seen as a consequence of the 'purpose' of the two types of knowledge. While scientific knowledge searches for universal significance, and often claims to be decontextualised, local knowledge is derived from a physical and sociocultural context and often focuses on its practical usefulness (Briggs 2005). Hence, the different knowledges are not 'meant' to be in accordance, because they are the outcome of different knowledge systems (Nightingale 2003).

The purpose of this paper is to analyse how various actors - both pastoralists and researchers view the rationale and importance of pastoral mobility and presents issues of importance for understanding the use of mobility among Fulani of Ferlo. It is important to note that the aim of the present paper is not to offer a 'successful' or even a comprehensive analysis of local versus scientific knowledge regarding pastoral mobility. Rather, it is an attempt to present different knowledge systems 
and to show how we can learn from these different knowledge systems without integrating one system into another.

In order to do so, a number of different methods have been used. These methods are both qualitative and quantitative, but, more importantly, information gathered through these methods is used to understand both the scientific and the local knowledge systems. The empirical basis of the paper is a case study from the Ferlo, which is the pastoral region of Senegal. Ferlo can be regarded as a 'critical' or an 'extreme' case - in Flyvbjerg's terminology (1991) of the Sahelian pastoral way of life. By extreme is meant a pastoral way of life that is not subsistence oriented, where the choice of livestock is influenced by market opportunities, and where pastoralists become increasingly more commercial. Hence, Ferlo is an area dominated by a 'modern' pastoral way of life. By studying pastoral mobility in Ferlo, an idea about Sahelian pastoralists' use of mobility in the future can be obtained.

To that end, the remainder of the paper is organised as follows. First, the idea of knowledge systems is explained; then follows a section on study area and methods. The subsequent two sections analyse knowledge systems - first the rationale and importance of pastoral mobility according to the pastoralists themselves, and then according to range ecologists. In the fifth section, pastoral mobility in Ferlo is analysed thematically and issues of importance for understanding the use of mobility among Fulani are presented. Finally, there are some concluding remarks.

\section{Knowledge systems}

Pivotal to the arguments developed in this paper is the idea that different knowledge systems exist. Hence, it builds on the concept of partial and situated knowledges developed by Haraway (1991) and embraced by a number of researchers (e.g. Mountz 2002; Rose 1997). It is central to these thoughts that certain constructions of knowledge function in particular ways, and, when asking a particular question, different constructions of knowledge will provide different information. Hence, knowledge is partial and linked to the contexts in which it is created (Nightingale 2003). This is in line with poststructuralist and postmodernist ideas that there is no single 'truth' as knowledge is socially constructed (Nygren 1999). This, however, does not mean that all knowledge systems are created equal in the context of a particular research question.

While there has been a tendency for scientific knowledge to be regarded as 'objective' and 'correct', scientific knowledge is still only a competing knowledge system, i.e. it is constructed within a certain setting. As noted by Briggs (2005, 104) 'Western science is as much socially constructed as indigenous knowledge'. The idea that scientific knowledge is subject to change and does not just constitute the building blocks of truth is not a legacy of postmodernism; Kuhn (1962), for instance, discussed this in his The structure of scientific revolutions. He also showed how research is conducted within a certain construction of knowledge with its own set of rules. In this paper, the term 'knowledge system' will be used for covering knowledge constructed within one set of ideas these being 'indigenous/local' or 'scientific'.

Hence, scientific knowledge can be seen as one knowledge system, or as many systems, depending on whether it has been constructed within one set of ideas or it is the outcome of different sciences. The competition between different scientific knowledge systems is analysed in the acclaimed The lie of the land, edited by Leach and Mearns (1996). In this book, a number of scholars criticise and challenge the so-called received or conventional wisdom on the African environment. The authors call for a sharper focus on local knowledge and argue that this should be included in order to understand both present and future land use.

Consequently, local knowledge can be considered as another knowledge system. Similar to scientific knowledge, local knowledge is not just one system. Different 'local people' have different world views and thus different knowledge systems. Also, as pointed out by Escobar (2001), it is important to bear in mind that local knowledge is fluid and dynamic since it develops as an integral part of the surrounding society. ${ }^{2}$ As explained by Milton (1997), the focus on people's own views and understanding began in the 1960s, when researchers, mainly anthropologists, 'became increasingly interested in understanding people's own perceptions and interpretations of the world ... because they form the appropriate context in which to analyse people's actions and decision-making process' (1997, 484). As argued by Briggs and Sharp (2004), the increasing interest in indigenous knowledge can also be seen as an attempt to produce more effective development strategies after the failure of top-down development. Indigenous knowledge has therefore been accredited increasing importance and wisdom.

For decades, rainforest Indians have been the symbol of local communities possessing primordial environmental wisdom (Nygren 1999). Pastoralists, however, remained scapegoats, accused of environmental malpractice until the advent of the new rangeland paradigm. Following this, many studies of pastoralists emphasised the actions of pastoralists were rational and the pastoralists were subsequently 
ascribed what has been labelled 'primitive ecological wisdom'. According to Milton (1996), the idea of 'primitive ecological wisdom' is common in the dominant discourse in environmental research. This has also been pointed out by Briggs (2005), Forsyth (1996) and Nygren (1999), who see a tendency among researchers to romanticise local knowledge (often labelled 'indigenous' knowledge). It means that non-industrial people, including pastoralists, supposedly have an environmental understanding, which renders them capable of living in a fine adaptation to the environment. Milton explains that this notion of 'primitive ecological wisdom' is not correct: 'Some of them may live their lives in ways that are environmentally sound, but ecological balance, where it exists, is an incidental consequence of human activities and other factors, rather than being an ideal or a goal that is actively pursued' (Milton 1996, 113). ${ }^{3}$ Likewise Briggs (2005, 100) has noted 'indigenous knowledge becomes central to later debates about sustainable development because of the way in which such knowledge has apparently allowed people to live in harmony with nature for generations'. This is not to say that local knowledge, accumulated over generations, is worthless, but rather to underline that it is a knowledge system and cannot just be integrated with other knowledge systems. Likewise, local knowledge should not be measured with scientific yardsticks, to use the terminology of Kaschula et al. (2005). Like scientific knowledge, local knowledge is based on certain conceptualisations and these are unlikely to correspond with the scientific ones. Therefore it is necessary to address these and deconstruct the underlying worldview. Using pastoralist mobility as an example, it is necessary to understand both the role which mobility plays in the pastoral way of life and how it is used.

Through the 1990s, the increasing interest in local environmental knowledge led to policy recommendations; several examples are found in Bush base: forest farm edited by Croll and Parkin (1992). Different case studies are used to illustrate the role of human cultural imagination in the use of environmental resources and the authors argue that development programmes should place their centre of appreciation on local knowledge, or what they call people's cultural understandings of their environment. Following this and other similar calls, it has become popular to use local knowledge in natural resource management recommendations (see, e.g., Beckford and Barker 2007; Behnke and Scoones 1993; Niamir-Fuller 1999). In the present context, it is argued that pastoralists' perspectives should be included in research and development processes in order to understand (future) dynamics of the pastoral way of life and their natural resource management. It is not enough to find out that pastoral mobility is rational from an ecological point of view, because as long as we do not know pastoralists' rationale for using mobility, we do not know if they will continue with this practice in the future. Consequently, it is difficult to make policy recommendations without knowing both the scientific and the local perspective.

It is, however, not straightforward to work with different knowledge systems. The problem of reconciling local knowledge with scientific knowledge has been discussed in Kaschula et al. (2005). One way to work with different knowledge systems is to use scientific knowledge to validate local knowledge. This is done by comparing data on a certain event or phenomenon derived from the two different types of knowledge. If it is found that the local knowledge has yielded 'correct' results, then the local knowledge can be used to fill gaps in scientific knowledge (e.g. Lykke 2000). This is quite common in natural resource management studies which have a natural science background and which are less influenced by postmodern approaches. Here one knowledge system - the scientific - is ascribed more credence or validity.

Another approach is demonstrated by Thomas and Twyman (2004) in their study of scientific and local knowledge of land degradation and change in the Kalahari. They find that it is unhelpful to juxtapose one form of knowledge against another as a test of validity. They argue that a more constructive way is to attribute more power to local communities and use local knowledge as a starting point in research, and then to use scientific knowledge to extend the research. This approach is used in the present study.

\section{Study area and methods}

Historically, the rangelands of Ferlo have been utilised as a pastoral grazing area due to the low and variable precipitation and lack of permanent water supplies, which made cultivation and permanent settlement difficult. In the rainy season, when pasture in the area was abundant, Ferlo served as a grazing reserve for mobile pastoralists pursuing large-scale migrations. As temporary water holes (ponds) dried out during the dry season, pastoralists moved north to the Senegalese River valley or south and west to the so-called Peanut Basin (Weicker 1993). In the 1950s, the French colonial administration dug the first boreholes in Ferlo, which meant that the area could be used on a more permanent basis. The possibility of staying in the area during the dry season meant that pastoralists became semi-sedentary (Ba 1986). Rain-fed agriculture was taken up, especially in the southern 


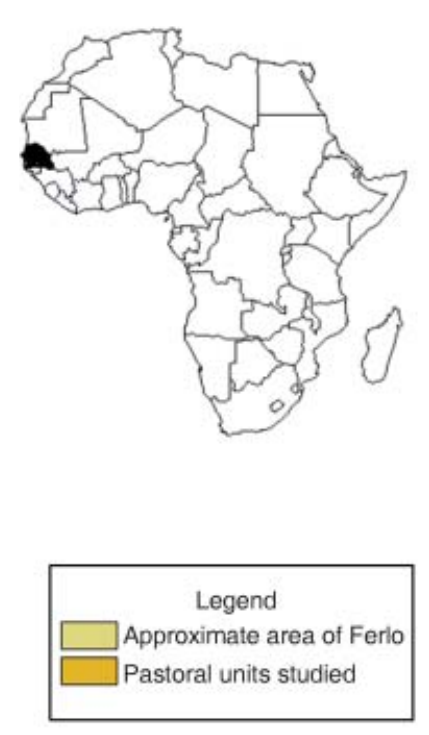

Figure 1 Map of Senegal and the pastoral area Ferlo. Fieldwork
as the foce lished (Touré 1990). Villages have grown around the boreholes. However, the pastoralists still live in the bush where they have rainy-season camps.

Before the drought in 1973, the majority of the pastoralists were subsistence oriented, relying on a combination of herding and rain-fed agriculture. The herd mainly consisted of cattle for milk and a few sheep and goats (Sutter 1987). The drought years in the mid-1970s and mid-1980s profoundly influenced the livelihood strategies of the pastoralists. Many pastoralists do not find cultivation worthwhile anymore, and they redirected the production towards more livestock rearing, especially with a greater reliance on sheep and an increased commercialisation of their activities. This influences the rationale for and use of mobility. Recently, parts of Ferlo have been divided into resource management units following the boreholes and based on pastoral (not agricultural) resource management; these are called pastoral units (unité pastorales). In the middle of each pastoral unit is a watering point. The area belonging to a certain pastoral unit is the area closest to that watering point. Hence, even before the pastoral units were made, the pastoralists thought of these areas as different territories from where it was most rational to walk to a certain watering point. Therefore, although the pastoral units as administrative units are not of particular interest in the present paper, they serve as reference points of importance for the pastoralists in relation to their utilisation of natural resources.

The fieldwork was carried out in five pastoral units with the main emphasis on Téssékré in the middle of Ferlo, which has been characterised as the 'zone pastorale par exellence'. ${ }^{4}$ Téssékré is not typical of the general area; it is more correctly described as a 'pure' case. Located in the middle of Ferlo, it is predominantly pastoral and marked by Fulani culture - there is neither the influence from agriculturalists seen in the southern Ferlo, nor that from the irrigated agriculture along the River Senegal. The rainfall is average for the area. Figure 1 is a map of Senegal, showing Ferlo and the five pastoral units.

Téssékré was visited on five occasions over a period of $2 \frac{1}{2}$ years, from 1997 to 2000. The village of Téssékré is located around a borehole established in 1954. In 1997, two secondary water outlets, called antennas, were made. In the pastoral unit of Téssékré, the majority of the inhabitants are Fulani $(92 \%)$; the rest are Wolof (5\%) and Moor (3\%). The people living in the village itself are Moor and Wolof; they are merchants and some have animals as well. Some of the Fulani have shops and houses in the village even though they live in the bush. 
The fieldwork was concerned with the pastoralists who all live in the bush.

In order to understand the importance and use of pastoral mobility according to different knowledge systems, multi-methods have been used. These range from GPS measurements of cattle mobility to questionnaires and qualitative interviews with family members, as well as participatory observations. However, the local knowledge system is predominantly based on the fieldwork using a more inductive approach, ${ }^{5}$ while the scientific knowledge system is constructed using a more deductive approach based on the existing literature supplemented by information from the field.

\section{Key informant interviews}

The first source of information was interviews undertaken with key informants. These were individuals who had particular knowledges of the pastoral unit or the pastoral practices in Ferlo. In particular, the local administrators of the boreholes in the pastoral units were valuable informants. Interviews were made in the five pastoral units shown in Figure 1. Other key informants in Téssékré included the teacher, the medical doctor, the president of the rural committee, and an elderly man who recounted the history of the area.

\section{Questionnaires}

Questionnaire interviews were made with all Fulani heads (jomoro) of households $\left(\right.$ galle $^{6}$ ) present at the time; a total of 64 jomoro were interviewed using a structured questionnaire with a combination of qualitative and quantitative, open-ended questions. The questionnaire gave an overview of types and trends in pastoral activities and the use of mobility. It was clear, however, that the questionnaire contained questions that had not always been understood by all the respondents, and in these cases, it did not make sense to use the data for statistical measurements. Therefore, a more in-depth approach was needed.

\section{GPS experiment}

Nine pastoralists were selected to participate in an in-depth study of the use of mobility; they were given a GPS each for the purpose of mapping the spatial dimension of mobility. The local administrator chose those nine pastoralists based on two criteria defined by the author. Firstly, they should live in different parts of the pastoral unit, at varying distances from the borehole. Secondly, the pastoralists should be interested in and capable of learning how to use a GPS.
Starting in February 1999 and ending one year later, the nine pastoralists took GPS measurements of the location of their cattle one day, every week. Since the pastoralists did not herd their cattle every day, they were asked to move with the cattle one day every week to perform these measurements. Each daily record comprises approximately 10 measurements taken throughout the day. ${ }^{7}$ The pastoralists were asked to do more frequent measurements during transhumance periods. ${ }^{8}$ However, due to a higher workload during transhumance, this did not always happen and in some instances the dataset is made up of only a few recordings each day, even though the frequency of daily records is higher during these periods.

The GPS experiment also included participatory observations. All nine pastoralists were visited on a number of occasions; some were in their camps and others had to be found further afield on transhumance. The author joined all nine of them when they were herding and taking GPS measurements. This 'participatory herding' was very useful, both in ensuring that the measurements were made correctly and for providing insights into the pastoralists' practices and understanding of mobility. The GPS data were used for mapping the use of the space and achieving a quantitative overview of mobility. However, the data were also used indirectly for asking 'informed questions' regarding the use of mobility and mobility patterns.

\section{Qualitative interviews and observations}

Apart from the informal conversations made in relation to the GPS experiment, qualitative interviews were carried out with these nine pastoralists and their families. These interviews were unstructured but based on the construction of a life history (Mikkelsen 1995). As men are the decisionmakers with regard to mobility, it did not make much sense to ask women directly about the use of mobility they simply referred to their men anyway. Instead, qualitative focus group interviews were conducted with women focusing on making a daily activity calendar. This was done in order to understand pastoral activities from their point of view. During these interviews, women made statements concerning their view and preferences in regard to mobility. While age-specific findings were not a part of the analysis, a qualitative interview was made with the children at school in order to let them express their experiences and expectations of the future. In addition, participatory observations were made in all five pastoral units, but in particular in the village of Téssékré and in the camps with the nine GPS pastoralists. These participatory observations 


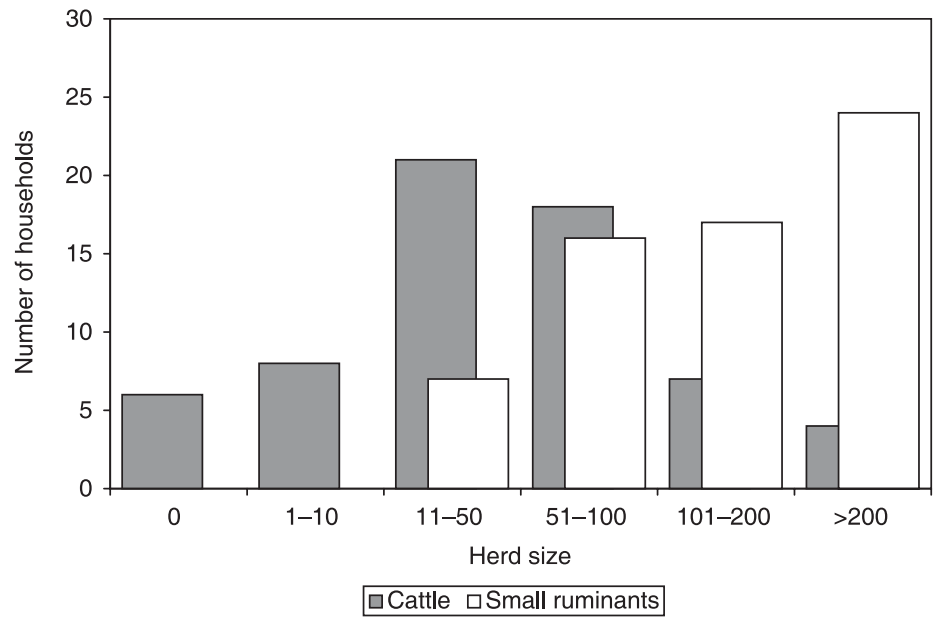

Figure 2 The herd size for cattle and small ruminants

provided insights into the socio-cultural fabric of daily life and herding practices.

The majority of the interviews were conducted in French and translated into Pulaar. A few interviewees spoke French well enough to omit translation. The interpreter was a Fulani from a town about $40 \mathrm{~km}$ from Téssékré. He had been recommended by a fellow researcher and was known as a dutiful and reliable translator. The interpretation was checked by presenting and discussing the main findings during focus groups meetings with the interviewees.

\section{The importance of mobility according to the pastoralists}

The various interviews, the GPS experiment, and the participatory observations in Téssékré gave rise to the following analysis of the pastoralists' rationale for and use of mobility. First, it is important to point out that the pastoralists in Ferlo use mobility quite differently depending on their household size/ labour availability, herd composition, herding patterns, involvement in other activities, as well as wider values and preferences in life. Figure 2 shows the herd size for cattle and small ruminants respectively.

Herd composition is a very important factor, and especially so since some pastoralists have begun to raise the so-called 'Tabaski sheep'. These are young male sheep, rams, which are raised for commercial purposes. They are sold just before the Muslim feast called Tabaski in Senegal and id-al-adha in Arabic. ${ }^{9}$ Pastoralists with Tabaski sheep will make sure that the rams are well fed so they can earn a good price at the right time. In this respect, the Tabaski sheep are quite different from the rest of the livestock, which are considered part of the family herd and usually not cared for in the same way. Hence, Tabaski sheep are quite mobile and transhumance is often used in order to make sure that the sheep get to the best pasture and are fat just before the sale. Hence, it is fairly labour intensive to raise Tabaski sheep.

While it is fairly labour intensive to raise Tabaski sheep, the fieldwork also showed that there is a tendency to decrease the labour input for pastoral activities. For pastoralists involved in the market economy, for instance, it is widespread to use an economic surplus to pay a herder for taking the livestock on transhumance. Decreased labour input has also been noted by other researchers of Ferlo. Touré (1988) mentions that the establishment of boreholes reduced the time spent on transhumance and on digging wells. Sutter (1987) also notes that the decrease in transhumance and absence of herding have changed the labour input and quotes an elderly herder: 'all our young people know how to do today is hang around the teapot' (Sutter 1987, 212). This change in attitude was confirmed in the present study. The pastoralists in Téssékré stated that the younger generation has a different attitude towards working. For instance, the elders prefer to herd cattle, while the younger generation finds it unnecessary, because cattle theft is not a problem. Small ruminants, however, are still herded all year, because these can get lost, stolen or eaten by jackals. Depending upon the strategy of the household, the small ruminants are herded by the children, young men, or a paid herder. For Tabaski pastoralists, herding is an investment in the 'capital stock' and they are not likely to involve their young children as herders. 
Table 1 Type of transhumance and the corresponding season, direction and duration

\begin{tabular}{llll}
\hline Type & Season & Direction & Duration \\
\hline Meeting the rain & Near rainy season, cen seldé & $\begin{array}{l}\text { South, where the first } \\
\text { rain falls } \\
\text { Anywhere }\end{array}$ & Until the rain begins \\
Better pasture elsewhere & $\begin{array}{l}\text { Usually dry season, dabudé } \\
+ \text { thiédu } \\
\text { Any season, but usually dry season, } \\
\text { thiédu } \\
\text { Lack of pasture }\end{array}$ & $\begin{array}{l}\text { Anywhere } \\
\text { dabudé } \\
\text { Any season } \\
\text { pasture }\end{array}$ & $\begin{array}{l}\text { Any season } \\
\text { Disease } \\
\text { Lack of water }\end{array}$
\end{tabular}

The tendency is that the younger pastoralists in Téssékré prefer not to herd their cattle and to let their children or a paid herder take care of the small ruminants. As many use the time for resting instead, the lack of herding is not due to a labour shortage. Moreover, there is no competition for labour between agriculture and pastoralism because the majority of the pastoralists do not cultivate due to lack of rain - and they also explained that pastoral activities always have the highest priority. However, some had also stopped herding their cattle because they prefer having a shop instead; nevertheless the surplus from the shop is used for buying more cattle. Many pastoralists would rather stay at home than be involved in transhumance or even herd their cattle in the pastoral unit.

Considerations concerning labour availability were based upon the pastoralists' perceptions. For instance, one of the pastoralists in Téssékré explained that he did not have labour for herding Tabaski sheep even though he had three teenage sons. According to the pastoralist, however, the sons should become Marabous and were therefore sent to Qur'ân school. Hence, what at first glance seemed like a household with plenty of labour was in fact constrained, due to their preference for paying their religious duties, as the head of the household expressed it. This is further discussed in Adriansen (2006).

The pastoralists distinguished between two main types of mobility: daily mobility within the pastoral unit; and transhumance. The latter entails leaving the pastoral unit and making a temporary camp elsewhere and it is related to different seasons:

- Rainy season - ndungu (June-August).

- Cold dry season - dabudé (September-January).

- Hot dry season - thiédu (February-April).

- Near rainy season - cen sedlé/deminaré (May).
The seasons are similar to the findings from other studies from Ferlo (e.g. Ba 1986; Barral 1982) and from other Fulani communities (e.g. de Bruijn and van Dijk 1995). The pastoralists identified the following types of transhumance, which also are reasons for going on transhumance (Table 1).

The rationale for going on transhumance influences whether all or some of the animals are taken. If there is a lack of water or pasture, it is necessary to bring along all the livestock. In case of 'better pasture elsewhere' or 'meeting the rain', it is common only to take the cattle or only the sheep. Whichever livestock type is taken depends on the needs of the livestock and the strategy of the household.

An interesting point concerning Tabaski sheep mobility is the changing of the time of the 'id-aladha. The Muslim calendar is a lunar calendar, which means that the timing of the 'id-al-adha changes by 10-11 days every year. At the time of the fieldwork (1998-2000), 'id-al-adha was in March-April, which means the hot dry season when the pasture availability was limited and its quality was poor. Therefore, quite a few Tabaski pastoralists went on transhumance in this season. As this is the 'normal' time for transhumance for pasture, the author did not realise at first that the rationale for Tabaski sheep mobility was different from other types of livestock. In 2007, however, 'id-al-adha was in January, the cold dry season, and by 2018 it will be taking place in the rainy season. Consequently, the Tabaski pastoralists' willingness to go on transhumance with the sheep is likely to change; it is not shaped by resource availability alone. Hence, market opportunities provided by religious events may influence mobility.

Concerning mobility within the pastoral unit, this can be quite complex. The pastoralists in Ferlo have a rainy-season camp called rumaano. During 


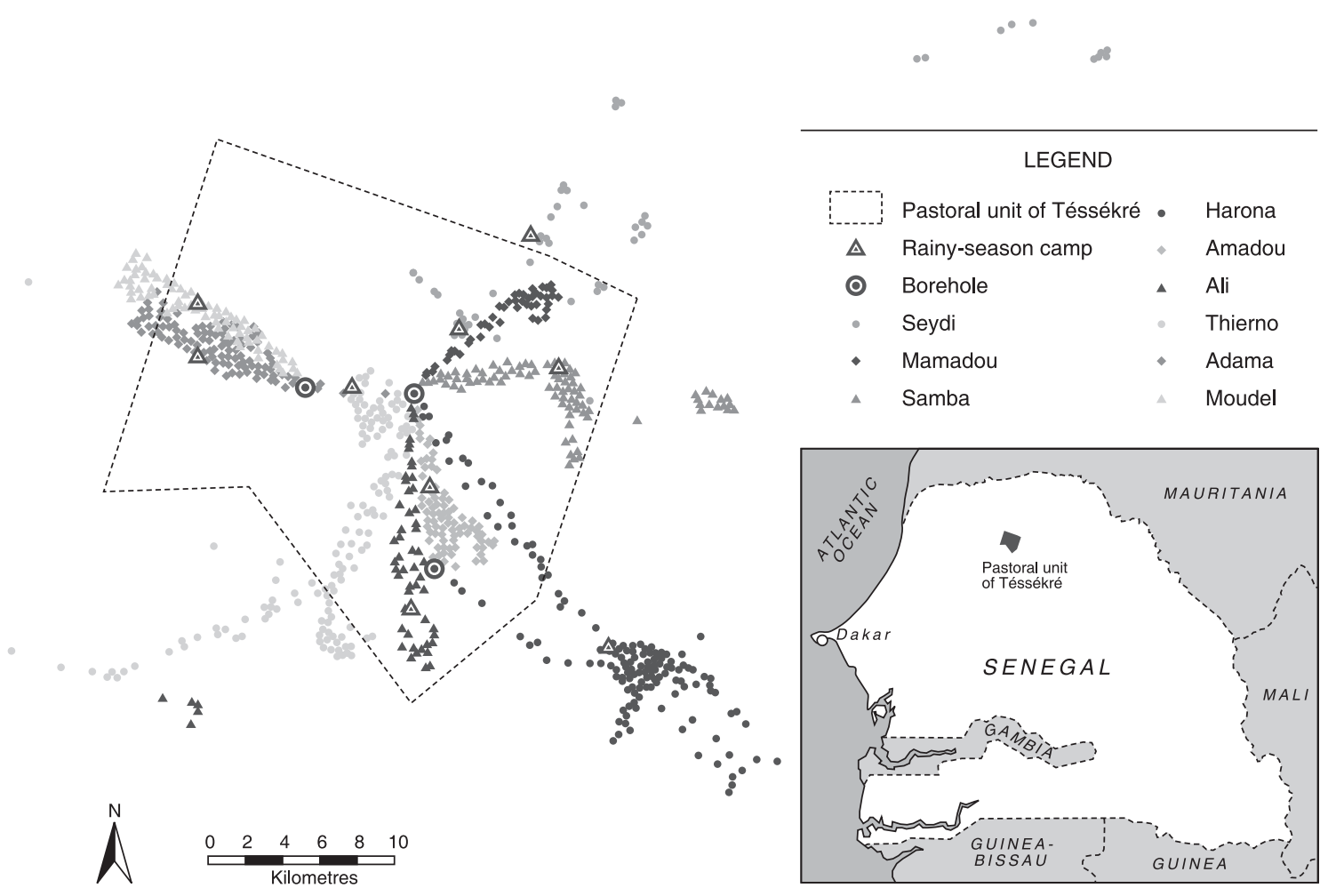

Figure 3 Results of the GPS measurements

the dry season, they may move around, but they return to the rumaano in the rainy season. Often, the rumaano is located near a pond, which means that water is available to the livestock until the pond dries out. As there is usually enough pasture during the rainy season, the livestock can stay close by the camp. This so-called 'micro-mobility' (a daily pulse predominantly within the pastoral unit) accounts for a large part of the total livestock mobility in Ferlo. After the ponds dry out, the cattle are watered every second day; one day they walk from the camp to the borehole, next day in the opposite direction sometimes crossing into the neighbouring pastoral unit. The small ruminants are watered every day. Depending on the livelihood strategy and how far away from the borehole the pastoralists live, they fetch water from the borehole in a large inner tube on a cart and bring it back to the camp where the small ruminants are watered. This is to spare the small ruminants the walk to the borehole where there is less pasture. ${ }^{10}$ By bringing the water to the camp, the small ruminants can graze where the pasture is most abundant. It is more labour intensive to water the small ruminants at the camp, but it seems to be a worthwhile investment, at least for the Tabaski pastoralists.
During the dry season, some pastoralists stay in the rumaano, while others are more inclined to move around in the pastoral unit. When pasture is abundant it is not necessary to move around much. In the hot dry season, it may be necessary to move more. Some prefer to walk longer distances with their animals every day, while others prefer to move the camp to an area that has not been utilised. Different types of animals may have different mobility; for instance, cattle are left to roam freely and small ruminants are herded. Some of these differences were seen in the GPS data (which only concern the mobility of cattle) and explained during the participatory observations during herding with the pastoralists. Figure 3 shows the GPS measurements.

\section{The importance of mobility according to scientists}

The scientific understanding of the importance of pastoral mobility has changed with - among other things - the understanding of dryland functioning, most importantly with the advent of the new rangeland paradigm in the late 1980s and early 1990s. For decades, the basis for studying dryland ecosystems in Africa, as well as in Australia and the USA, 
had been Clements' model of vegetation succession (Clements 1916), and the idea of equilibrium ecosystems and livestock density dependent limitations of primary production (Deshmukh 1986). With the new paradigm, researchers showed dryland ecosystems cannot be understood using the equilibrium theories. Instead, drylands are disequilibrium systems; this means that the productivity is controlled mainly by the highly variable precipitation. An equilibrium concept, such as carrying capacity, is not relevant in a disequilibrium system, because livestock numbers seldom reach densities high enough to influence vegetation productivity (Adriansen 1999). With the new understanding of ecosystem functioning followed a new understanding of pastoral knowledge (Warren 1995). Most importantly, customary tenure systems were no longer seen as leading to overexploitation as stipulated by Hardin in his famous 'tragedy of the commons' (1968). Also, the idea that pastoralists had an irrational attachment to cattle (a cattle complex), which led to an overstocking of the range, was revised. Instead, high livestock numbers were seen as rational in disequilibrium systems where opportunism is rational (Warren 1995).

Anomalies leading to this new understanding of pastoral practices occurred long before the paradigm shift. Anthropologists in particular (e.g. DysonHudson 1966; Evans-Pritchard 1940; Nicolaisen 1963; Stenning 1959) and others studying pastoral production systems (e.g. Gallais 1967; Johnson 1969) have pointed to the flexible strategies employed by pastoralists. With the appreciation of the disequilibrial nature of drylands, however, these findings were placed in a coherent context. Thus, the range ecologists' new view on drylands has been followed by an awareness of pastoral mobility as a sound response in highly variable and unpredictable climates.

The perception of pastoral mobility within the new rangeland paradigm can be summarised as follows. An important characteristic of tropical drylands is the heterogeneity of natural resources. Pastoral mobility implies that pastoralists can move to areas with pasture for their livestock. Movements in relation to resource availability can be seen as one type of mobility. Pastoral mobility also means that the effect of unforeseen events (e.g. outbreak of disease, bush fire, locust attack) can be mitigated (Niamir-Fuller 1998; Thébaud and Batterbury 2001; Scoones 1995b). This can be seen as another type of mobility. The pastoralists in Téssékré use both types of mobility, as seen in Table 1.

The efficient use of natural resources requires pastoral mobility patterns at different scales, depending on the spatial and temporal variability of the resources and adaptation to other elements of the production system. Depending on the degree of variability, pastoral mobility patterns can be more or less regular. In highly variable and unpredictable ecosystems, large-scale pastoral mobility is a common phenomenon. In these areas cultivation is rare and the population very mobile. In less variable and unpredictable ecosystems, where cultivation is more common (often occurring as agro-pastoralism) and the population more sedentary, variability in resources can often be met by smallscale migration to local key resources and harvested fields, or by irregular large-scale migrations (Scoones 1995b). Key resources or 'wet-lands in dry-lands' are highly productive patches found in low-lying areas, along rivers or lakes. Here good grazing can be found when the quality and quantity of the rangeland have declined during the dry season (Bayer and Waters-Bayer 1995). Historically, the land along the Senegal River has served as such a key resource. Now, however, the area has been converted into large irrigated fields with little space for pastoral activities.

Pastoral mobility between different agro-ecological zones means that more livestock can be kept, than if the livestock was kept solely in each of the zones. Many studies from dryland West Africa provide examples of how pastoral mobility between different agro-ecological zones can be used for making an efficient use of variable natural resources. By using drier areas during the wet season and more humid areas during the dry season, livestock are ensured both high-quality and sufficient grazing. However, livestock keeping in the more humid zone is complicated by increased disease risk. This, combined with the problem of having livestock near fields in the growing season, means that some livestock owners in more humid areas are often willing to hire pastoralists to herd their livestock into the drier areas during the cultivation or wet season (de Leeuw et al. 1993). This is seen in the southernmost part of Ferlo, close to agricultural areas.

Even though pastoral mobility seems like a sound way of making the most of the variable dryland areas of West Africa, a number of factors are hindering this. For example, agricultural encroachment means that pastoral areas are in decline, and Ferlo is a case in point. Here agriculture is encroaching both from the south and the north where the irrigated area along the Senegal River is expanding. In addition, the right to land has been linked to the obligation to 'mise en valeur', i.e. to ensure a productive use of the land, common in many Sahelian countries. Often pastoral production is not considered to be a productive use of the land, and this has forced pastoralists to cultivate the areas they use in order to obtain land rights (Thébaud 1995). 
To sum up, the new rangeland paradigm has shown that pastoral mobility is a flexible response that allows use of harsh environments. It should be kept in mind that even though many pastoralists have become semi-sedentary, mobility is still an important part of the livestock-rearing strategy. Hence, mobility of livestock and of pastoralists is not necessarily the same thing. The distances covered by the livestock often amount to $20 \mathrm{~km}$ per day, returning to the camp/village almost every night (e.g. Adriansen and Nielsen 2002; Milleville 1991; Touré 1990). Although many pastoralists employ short distance mobility, constraints on pastoral mobility, particularly borders, tenure regulations, cultivated areas etc., hamper the whole pastoral system. Thus, what may appear as a minor constraint in a small area that may not even be used very often can have major implications for the utilisation of resources in other areas. Therefore, pastoral mobility should be unconstrained for the optimal utilisation of variable resources.

In Téssékré, the explicit reasons given for utilising transhumance all related to the search for pasture and water. There were some variations in the responses when it came to pasture, because some pastoralists move in order to find better quality resources (a pull effect), and others because the quantity of these is lacking (a push effect). Pastoralists who own Tabaski sheep used mobility in order to find better quality pasture, while the majority of other pastoralists only went in the case of need. The answers could all be interpreted as illustrating the pastoralists' attempts to balance the variability of the resources. The interviews demonstrated, however, that the pastoralists did not have environmental sustainability as the point of departure for their considerations on mobility. Instead, mobility was discussed from the point of view of livestock needs. There is a difference between these two perspectives; the pastoralists of Ferlo are not using mobility because it is ecologically rational. To them, mobility is a means to ensure the survival of the livestock, but this is not necessarily at odds with the scientific knowledge of pastoral mobility when it comes to the everyday use of mobility. Nevertheless, it is important to bear in mind that when the rationale is different, pastoralists' everyday use of mobility can change in a way that is no longer in accordance with the scientifically rational way of using mobility.

\section{The use of pastoral mobility in Ferlo}

While the previous sections illustrate the importance of pastoral mobility according to different actors, this section uses a different level of abstraction. Here the use of mobility in Ferlo is analysed focusing on different issues. The two knowledge systems presented in the previous sections do not coincide, but they are not in direct conflict either; rather they provide different types of knowledge about pastoral mobility. As mentioned, there are a number of different scientific and local knowledge systems. The local knowledge presented earlier can be considered to exist as one or more systems, depending on the scale of the study. Looking beyond village level, a number of local knowledge systems can be found, but for the purpose of this paper, the local knowledge in Téssékré has been considered as one knowledge system. In this section, knowledge from a scientific or 'Western' system, which is not the new rangeland paradigm, will also be presented.

\section{Spatial and quantitative aspects of mobility}

Considering the findings of the new rangeland paradigm, it is important to distinguish between the mobility of people and of livestock. In Ferlo, the pastoralists have become semi-sedentary and the cattle are left to roam freely as there are no cattle theft. This means that there is no link between the mobility of humans and cattle, as long as the herd remains within the pastoral unit. Small ruminants are usually herded mostly by children or young men. Again, mobility of pastoralists and mobility of their herds are two different things.

GPS proved a valuable tool for monitoring the livestock mobility in Ferlo. The data collection protocol was designed to provide GPS measurements on the distances covered both during daily mobility and during transhumance, as well as to provide an overview of the spatial distribution of the cattle. When the GPS data were analysed in a GIS, a number of interesting features were found. Some of these can be seen in Figure 3. The spatial data revealed the widespread use of micro-mobility, which was used by all nine pastoralists, usually with the rainy-season camp as the point of departure. It was also clear how the spatial utilisation changed according to the drying out of ponds and changes in vegetation availability. The data further showed that the construction of a new temporary camp within the territory of Téssékré was common, as three out of the nine pastoralists had done that in the year in question, which was a typical year in terms of mobility. Two pastoralists had employed transhumance but only to a neighbouring pastoral unit. Seven out of the nine pastoralists utilised pasture just outside the pastoral unit of Téssékré during the daily mobility. Quantitative measurements of mobility revealed that cattle walked an average of $5000 \mathrm{~km}$ per year, mostly within the pastoral unit. This illustrates that cattle are quite 
mobile, even though the pastoralists themselves have become semi-sedentary. The difference in yearly average between pastoralists who employ transhumance and those who do not is small. This is due to the fact that the cattle walk an average of $14 \mathrm{~km}$ per day, less in the rainy season and when water can be provided from the ponds and more in the dry season. The daily distance does not change much during transhumance, which usually is during the dry season when the daily distance is already large. Hence, the quantitative measurements of mobility need to be contextualised. For an in-depth discussion of the potential of using GPS as well as the methodological problems involved, please refer to Adriansen and Nielsen (2002 2006).

From the perspective of range ecology, the spatial distribution of stock is also interesting because a high spatio-temporal variability in natural resources can be exploited by moving livestock around in the landscape. When the GPS data are integrated with satellite data in a GIS, this can reveal the relationship between natural resource availability and its exploitation (Adriansen and Nielsen 2006). Further, the GPS data were used for asking informed questions. For instance, the data showed that one of the pastoralists had been in the neighbouring pastoral unit for a fortnight. He was then asked why he had gone there and who had accompanied him. The pastoralist explained that he had left Téssékré because the pump at the borehole was out of order, and that he had returned when it was fixed. Hence, he had left due to lack of water, which is one of the explanations/types seen in Table 1. In this way, the GPS data served as a means for clarifying conceptualisations because they provided a reference point that both the pastoralists and the author could refer to when discussing mobility types.

\section{Mobility and cultural construction of identity}

Both before and after the new rangeland paradigm, mobility or the nomadic aspect of pastoralism has been considered very important for pastoral identity, or even as defining this identity (Cole 1975; DysonHudson and Dyson-Hudson 1980; Loftsdottír 2001; Salzman 1995). This view of mobility can be found among some pastoral groups in the recognition of the most mobile pastoralists as the most noble (Chatty 1986). However, the pastoralists in Téssékré did not relate mobility to their (ethnic) identity. ${ }^{11}$ Instead, identity is more strongly linked to livestock, especially the cattle:

My father had cattle and it is to be Fulani.

I have cattle because I'm Fulani - a Fulani without cattle is like a woman without jewels.
Mobility is only important in the context of cattle for the Fulani identity in Ferlo. Moreover, the widespread use of hired herders for going on transhumance illustrates that many pastoralists do not want to go on transhumance if they can avoid it. Thus, while the majority of the pastoralists explained that ownership of cattle was necessary for their Fulani identity, nobody expressed mobility as a necessity for their identity. The life-history interviews demonstrated that the pastoralists remembered when they had been given their first sheep/goat and their first cow, and by whom. These were important moments in life. In contrast, nobody ascribed importance to transhumance episodes. This was also clear when discussing mobility. The pastoralists were asked why they had decided to stay where they stayed at the moment. When they did not stay in the rumaano, they explained that the needs of the livestock had forced them to move. They elaborated that they had to be where the pasture was right for their livestock:

To look after the livestock is the work of the Fulani.

Women expressed a dislike for transhumance, because this gave them extra work, such as making huts. Another reason, which was discussed less candidly, was that competition arose between the women in case of transhumance. As many of the men in Téssékré had more than one wife, transhumance often meant that one or two women would join the husband, while the others had to stay behind with the weak and elderly. Despite the increased workload during transhumance, most women preferred to join their husband. For men, however, transhumance also increased the workload, as it was necessary to herd the livestock during transhumance - in contrast to the situation at 'home'. This can explain the widespread use of paid herders.

\section{The shaping of space into place}

Concepts such as 'sense of belonging' or 'shaping of space into place ${ }^{\prime 2}$ (Cresswell 2004; Tuan 1977) can be used for understanding people with shifting homes (e.g. migrants and nomadic pastoralists) and their use and conceptualisation of mobility. These are concepts derived from a 'Western', scientific knowledge system, although not from the system labelled the new rangeland paradigm, which has already been mentioned. There is an increasing interest in the idea that space is culturally constructed, especially among human geographers (Unwin 2000). This interest has led to studies of the relationship between the construction of identity and the image of home/place versus outside/space (e.g. Buttimer 1998; McHugh 2000). Within this 
tradition, place is seen as a meaningful location. Consequently, looking at place is a way of understanding the world; when analysing the world as a world of places, attachments and connections between people and place can be seen (Cresswell 2004). Using these debates, an understanding of the use of the territory of the pastoral unit was obtained. This was done using qualitative methods, such as observations and interviews, but interestingly the GPS experiment could also be used.

Researchers studying Fulani pastoralists have found that wuro, the camp, and ladde, the bush or non-human space, are central concepts when trying to understand how Fulani experience different locations (Bovin 1991; de Bruijn and van Dijk 1995; Loftsdottír 2001). Wuro and ladde can be said to constitute culturally constructed categories among the Fulani to distinguish between localities, their spaces and places. Using the idea that places have spaces between them (Cresswell 2004), the shaping of space into place could be observed in relation to constructing a camp, i.e. the shaping of space/bush/ladde into place/camp/wuro. The first attempt to change space into place is to clear a circular spot where the hut is to be made. The living place must not have grass on it. This applies to both the rainy-season camp, the rumaano, and the temporary camps. However, there was a difference between two types of camps. The area of the rumaano is often fenced and, in the rumaano, the huts are of a permanent character. They can be made of clay/clay bricks, but straw huts are still the most common. Usually the huts are circular with a cone-shaped roof. The roofs consist of a wooden frame covered with straw. A professional artisan is paid to make this wooden frame. Hence, the pastoralists choose to invest money in the construction of the rumaano. In the temporary camps, the huts are of a less permanent character. Women are responsible for making these huts, which are dome shaped and made out of material found locally.

The shaping of space into place could also be recognised at larger scales. There is a sense of belonging not only to the rumaano, but also to the whole pastoral unit. For instance, the pastoralists in Téssékré only said that they have been on transhumance when they have left the pastoral unit; movements and construction of a temporary camp within the pastoral unit did not count as transhumance. Within the pastoral unit, the family can set up the camp anywhere, and it is still considered home. There may be a number of reasons why the pastoralists prefer to stay within the pastoral unit, and why they consider the whole area of the unit as their place. First of all, within the pastoral unit, the cattle know the area and herding is not necessary. Also, the pastoralists know the landscape, and consequently the resource availability. This feeling of intimate knowledge of an area may be one of the mechanisms shaping space into place. Another reason for remaining in the pastoral unit may be that the price of the water is cheaper there compared with the price at other boreholes. Hence, the shaping of space into place affects the use of mobility. It means that leaving the rumaano is not considered a 'barrier', as long as the temporary camp is made within the pastoral unit.

For women, however, the workload increases as soon as they leave the rumaano and have to make a temporary camp, but they still seem to distinguish between the pastoral unit and 'outside'. This may be due to the fact that fetching water usually is the women's chore. As long as they remain within the pastoral unit, they fetch water from the usual borehole. Going to this borehole gives them an opportunity to talk with friends and family and a few days a week there are schooling opportunities for women in Téssékré. During transhumance, even if it is just to the neighbouring pastoral unit, these social networks are interrupted.

This section has attempted to provide an understanding of the use of pastoral mobility in Ferlo. This is by no means a 'complete picture' of pastoral mobility, but it shows how knowledge systems can be used for providing 'different pictures' of the use and understanding of mobility. One picture shows that it is important to distinguish between the mobility of pastoralists and that of their herd; even though the pastoralists of northern Senegal have become semi-sedentary, their herds are still quite mobile. Hence, the fact that pastoralists become semi-sedentary does not necessarily mean that the livestock also become less mobile.

Another picture shows that mobility is not of importance for the pastoralists' ethnic identity in Ferlo. For them, cattle are central to their identity as Fulani. Mobility becomes central only for the well-being of the animals. The use of paid herders for transhumance demonstrates that the pastoralists do appreciate mobility per se. Hence, increased integration into the market economy and possibilities to buy fodder may change the use of transhumance in the future. This links up with the last picture concerning the pastoralists' perception of different types of territory, here labelled space and place. In Téssékré, the pastoralists are willing to move around within a small territory, which they consider their place, but are unwilling to employ large-scale mobility themselves.

\section{Concluding remarks}

Local knowledge has often been portrayed as either a scapegoat or panacea for sustainable environmental 
development - pastoralists are a case in point. After years of ignoring or disregarding local knowledge, the 1990 s saw an increasing interest in integrating local perspectives in natural resource management. As this paper has tried to explain, it is not without problems, however, to combine local and scientific knowledge. In the paper, the concept of knowledge systems was applied to emphasise that all knowledge - including scientific knowledge - is partial and linked to the context in which it is created.

The case study from Ferlo demonstrates how multi-methods and different knowledge systems can be used for understanding pastoral mobility. When combining different methods, it is important to make sure that the results from the different methods are robust on their own terms.

Two knowledge systems were the focal point for the study. The scientific knowledge system was the new rangeland paradigm, which has shown how pastoral mobility is ecologically rational in drylands. However, this does not explain the pastoralists' reasons for using mobility nor their perceptions of it. Therefore, the pastoralists' own knowledge system was studied with regard to mobility. For the pastoralists, it is rational to move livestock to the areas with available natural resources. This is in accordance with science. However, the pastoralists' rationale for using mobility is based on livestock needs (and not on conservation needs), and in this way it is different from the scientific knowledge system. Pastoralists use mobility both to balance variability in resources and to fatten Tabaski sheep - hence, mobility is also used when science does not find it rational.

For the pastoralists, it was not the actual number of kilometres travelled that defined mobility. They will try to find pasture within the pastoral unit and pursue small-scale mobility instead of moving outside the pastoral unit. The majority of the pastoralists only went on transhumance with reluctance, and, if they could afford it, they used a paid herder. Hence, even if a family found mobility to be important for their household strategy, this did not necessarily mean that they themselves practiced it. Nevertheless, micro-mobility with the construction of a new temporary camp within the territory of Téssékré occurred on a number of occasions. In order to understand the use of micro-mobility, it was necessary to address the pastoralists' perception of the territory.

In both knowledge systems, it is important to distinguish between mobility of humans and of animals, and sometimes between different types of livestock such as Tabaski sheep. In line with this, quantification of the spatial distribution of mobility becomes interesting for scientists. However, when interpreting the use of mobility, Fulani perspectives must be included, otherwise we may not understand why they move the way they do, and if they will continue to do so in the future.

\section{Notes}

1 The first papers suggesting a 'new rangeland paradigm' were published in the late 1980s (e.g. Ellis and Swift 1988; Westoby et al. 1989). Through the 1990s, the new rangeland paradigm was discussed in a number of publications with increasing focus on pastoral management in relation to dryland functioning (e.g. Behnke et al. 1993; Scoones 1995a; Warren 1995).

2 In this paper, local knowledge may be defined as: 'dynamic and complex bodies of know-how, practices and skills that are developed and sustained by people/communities with shared histories and experiences ... It is knowledge which is developed and used over time by local people and is influenced by environmental and socioeconomic realities' (Beckford and Barker 2007, 118). Often local and indigenous knowledge is used interchangeably. In this paper, the term local knowledge is preferred in order to emphasise its dynamic nature which means that people may have adapted knowledge derived from other knowledge systems and hence is not necessarily purely 'indigenous'. As noted by Briggs, indigenous knowledge may no longer exist in an untouched, pristine form. Therefore it may be more precise to label such knowledge local knowledge.

3 This quote does not relate to pastoralists in particular, but to 'non-industrial people' in general.

4 This characterisation was made by the pastoral expert Oussouby Touré of the 'Centre de Suivi Ecologique' in Dakar.

5 Please note that the local knowledge of the pastoralists in Ferlo presented here is the author's interpretation of the pastoralists' knowledge system. Moreover, this knowledge system is not 'traditional', static or without influence from the surrounding community or from the scientific knowledge system for that matter. It is a knowledge system that has developed over centuries and still changes.

6 Weicker $(1993,71)$ has explained the term in the Ferlo context: 'Le galle constitue l'unité économique fondamentale dans la structure social des Peul. Le terme galle désigne en Pulaar d'abord la clôture qui entoure le lieu d'habitation réel d'une grande famille, pour le délimiter des champs et pâturages situés aux alentours' (italics in original).

7 The method does not include night grazing, which other studies (e.g. Ayantunde et al. 2000) have found to be important for cattle. It was too tiring for the pastoralists to follow the cattle at night, but information on the herd's whereabouts during the night was gained through interviews.

8 The original meaning of transhumance is seasonal migration from lowland winter pastures to highland summer pastures. However, it is also used to denote seasonal migrations from a permanent homestead (Widstrand 1975). 
In the present context, transhumance means movements outside the pastoral unit, usually related to dry-season pasture shortage. The word mobility refers to any kind of movement, independent of the season, whether this is within the pastoral unit or occasional 'crisis' movements outside the pastoral unit or even outside Ferlo.

9 Id-al-adha, which is the 10th day of the Muslim pilgrimage month, is a sacrificial feast in remembrance of Ibrahim, who was told by God to sacrifice his son (Qur'ân, sura 37, 103-8). This day Muslims bring an offering, usually a sheep. Both pilgrims in Mecca and Muslims 'at home' celebrate id-al-adha. This means that the demand for rams all over Muslim Africa and the Middle East is high at this time of the year.

10 Please refer to Juul (1996 1999) for an in-depth discussion of the importance of the tube for pastoral mobility and the development of pastoral strategies in Ferlo.

11 Concerning Fulani identity in Mali and Burkina Faso, the concept pulaaku has been mentioned as central (Bolwig and Paarup-Laursen forthcoming; Dupire 1970). Pulaaku includes the social and moral code that Fulani consider central to their ethnic identity (please refer to Bruijn and van Djik 1995, 199-201 for an overview of the usage of the concept in the literature). However, pulaaku was not used by the pastoralists in Ferlo and therefore the concept is not used in this paper.

12 A general discussion of 'space' and 'place' is beyond the scope of this paper. It suffices to say that space and place require each other for definition and 'space is more abstract than place' (Tuan 1977, 6), which means that while space is general, place is particular: 'space is everywhere, place is somewhere' (Taylor 1999, 10).

\section{References}

Adriansen H K 1999 Pastoral mobility as a response to climate variability in African drylands Danish Journal of Geography 99 1-10

Adriansen H K 2006 Continuity and change in pastoral livelihoods of Senegalese Fulani Agriculture and Human Values 23 215-29

Adriansen H K and Nielsen T T 2006 The geography of pastoral mobility: a spatio-temporal analysis of GPS data Sahelian Senegal Geolournal 64 177-88

Adriansen H K and Nielsen T T 2002 Going where the grass is greener: on the study of pastoral mobility in Ferlo, Senegal Human Ecology 30 215-26

Ayantunde A A, Williams T O, Udo H M J, Fernández-Rivera S, Hiernaux P and van Keulen H 2000 Herders' perceptions, practice, and problems of night grazing in the Sahel: case studies from Niger Human Ecology 28 109-30

Ba C 1986 Les Peuls du Senegal. Etude geographique Les Nouvelles Editions Africaines, Dakar

Barral H 1982 Le Ferlo des forages ORSTOM, Dakar

Bayer W and Waters-Bayer A 1995 Forage alternatives from range and field: pastoral forage management and improvement in the African drylands in Scoones I ed Living with uncertainty: new directions in pastoral development in Africa Intermediate Technology Publications, Exeter 58-78

Beckford C and Barker D 2007 The role and value of local knowledge in Jamaican agriculture: adaptation and change in small-scale farming The Geographical Journal 173 118-28

Behnke R H and Scoones I 1993 Rethinking range ecology: implications for rangeland management in Africa in Range ecology at disequilibrium: new models of natural variability and pastoral adaptation in African savannas Overseas Development Institute, Nottingham 153-72

Behnke R H, Scoones I and Kerven C eds 1993 Range ecology at disequilibrium: new models of natural variability and pastoral adaptation in African savannas Overseas Development Institute, Nottingham

Bollig M and Schulte A 1999 Environmental change and pastoral perceptions: degradation and indigenous knowledge in two African pastoral communities Human Ecology 27 493-514

Bolwig S and Paarup-Laursen B forthcoming Crisis identity and livelihood in the Sahel: historical change in status and income among Fulani Farmers Rimaybe and herders Fulbe in Northern Burkina Faso in Bovin $\mathbf{M}$ and Diallo $\mathbf{G}$ eds Culture and crisis in the Sahel The Scandinavian Institute of African Studies, Uppsala

Bovin M 1991 Spor i sandet in Dybbroe S, Møller P B, Olesen A, Vestergaard E and Vestergaard T E eds Klaus Khan Baba Aarhus Universitetsforlag, Esbjerg 134-53

Briggs J 2005 The use of indigenous knowledge in development: problems and challenges Progress in Development Studies 5 99-114

Briggs J and Sharp J 2004 Indigenous knowledges and development: a postcolonial caution Third World Quarterly 25 661-76

Buttimer A 1998 Geography's contested stories: changing states-of-the-art Tijdschrift voor Economische en Sociale Geografie 89 90-9

Campbell D, Lusch J, David P, Smucker T, Wangui A and Edna E 2005 Multiple methods in the study of driving forces of land use and land cover change: a case study of SE Kajiado District, Kenya Human Ecology 33 763-94

Chatty D 1986 From camel to truck: the Bedouin in the modern world Vantage Press, New York

Clements F 1916 Plant succession: an analysis of the development of vegetation Carnegie Institute Publications 242

Cole D P 1975 The nomads of the nomads: the Al Murrah Bedouin of the Empty Quarter Aldine Publishing Company, Chicago

Cresswell T 2004 Place: a short introduction Blackwell, Coventry Croll E and Parkin D eds 1992 Bush base: forest farm culture, environment and development Routledge, Chatham

de Bruijn M and van Dijk H 1995 Arid ways: cultural understandings of insecurity in Fulbe society Thela Publishers, Amsterdam

de Leeuw P N, Diarra L and Hiernaux P 1993 An analysis of the feed demand and supply for pastoral livestock: the Gourma region of Mali in Behnke $\mathbf{R} \mathbf{~ H}$, Scoones I and Kerven $\mathbf{C}$ eds Range ecology at disequilibrium - new models of natural variability and pastoral adaptation in African Savannas Overseas Development Institute, Nottingham 136-52 
Deshmukh I 1986 Ecology and tropical biology Blackwell, Palo Alto

Dupire M 1970 Organisation sociale des Peuls Plon, Paris

Dyson-Hudson N 1966 Karimojong politics Clarendon Press, Oxford

Dyson-Hudson R and Dyson-Hudson N 1980 Nomadic pastoralism Annual Review of Anthropology 9 15-61

Ellis J E and Swift D M 1988 Stability of African pastoral ecosystems: alternate paradigms and implications for development Journal of Range Management 41 450-9

Eriksen C 2007 Why do they burn the 'bush'? Fire, rural livelihoods, and conservation in Zambia The Geographical Journal $173242-56$

Escobar A 2001 Culture sits in places: reflections on globalism and subaltern strategies of localization Political Geography 20 139-74

Evans-Pritchard E E 1940 The Nuer: a description of the modes of livelihood and political institutions of Nilotic people Oxford University Press, Oxford

Flyvbjerg B 1991 Rationalitet og magt, det konkretes videnskab Vol 1 Akademisk forlag, Århus

Forsyth T 1996 Science, myth and knowledge: testing Himalayan environmental degradation in Thailand Geoforum 27 375-92

Gallais J 1967 Le delta intérieur du Niger Étude de géographie regionale Tombe I \& II Ifan, Dakar

Haraway D 1991 Simians, cyborgs and women Routledge, New York

Hardin G 1968 The tragedy of the commons Science 162 1243-8

Johnson D L 1969 The nature of nomadism - a comparative study of pastoral migration in southwestern Asia and northern Africa Research Paper No 118 Department of Geography, University of Chicago, Chicago

Juul K 1996 Post drought migration and technological innovations among Fulani herders in Senegal: the triumph of the tube! IIED Drylands Programme Issue Paper No. 64

Juul K 1999 Tubes, tenure and turbulence: the effects of drought related migration on tenure issues and resource management in northern Senegal PhD Dissertation, Roskilde university, Denmark

Kaschula S A, Twine W E and Scholes M C 2005 Coppice harvesting of fuelwood species on a South African common: utilizing scientific and indigenous knowledge in community based natural resource management Human Ecology 33 387-418

Kuhn T 1962 The structure of scientific revolutions University of Chicago Press, Chicago

Leach M and Mearns R eds 1996 The lie of the land: challenging received wisdom on the African environment James Currey and Heinemann, Exeter

Loftsdottír K 2001 Where my cord is buried: WoDaaBe use and conceptualization of land Journal of Political Ecology 8 $1-24$

Lykke A M 2000 Local perceptions of vegetation change and priorities for conservation of woody-savanna vegetation in Senegal Journal of Environmental Management 59 107-20

McHugh K E 2000 Inside, outside, upside down, backward, forward, round and round: a case for ethnographic studies in migration Progress in Human Geography 24 71-89

Mikkelsen B 1995 Methods for development work and research: a guide for practitioners Sage Publications, New Delhi

Milleville P 1991 Les systémes d'élevages in Claude J, Grouzis $\mathbf{M}$ and Milleville $\mathbf{P}$ eds Un espace Sahelien: La mare d'Oursi Burkina Faso ORSTOM, Paris 156-78

Milton K 1996 Environmentalism and cultural theory: exploring the role of anthropology in environmental discourses Routledge, St Ives

Milton K 1997 Ecologies: anthropology, culture and the environment International Social Science Journal 49 477-95

Mountz A 2002 Feminist politics, immigration, and academic identities Gender, Place and Culture 9 187-94

Niamir-Fuller M 1998 The resilience of pastoral herding in Sahelian Africa in Berkes F, Folke $\mathbf{C}$ and Colding $\mathbf{J}$ eds Linking social and ecological systems: management practices and social mechanisms for building resilience Cambridge University Press, Cambridge 250-84

Niamir-Fuller M ed 1999 Managing mobility in African rangelands: the legitimization of transhumance IT Publications, Exeter

Nicolaisen J 1963 Ecology and culture of the pastoral Tuareg National Museets Skrifter, Etnografisk Række IX København, The National Museum of Copenhagen

Nielsen T T and Adriansen H K 2005 Government policies and land degradation in the Middle East Land Degradation and Development 16 151-61

Nightingale A 2003 A feminist in the forest: situated knowledges and mixing methods in natural resource management ACME 2 78-90

Nygren A 1999 Local knowledge in the environment-development discourse: from dichotomies to situated knowledges Critique of Anthropology 19 267-88

Oba G and Kotile G 2001 Assessments of landscape level degradation in southern Ethiopia: pastoralists versus ecologists Land Degradation \& Development 12 461-75

Rose G 1997 Situating knowledges: positionality reflexivity and other tactics Progress in Human Geography 21 305-20

Salzman P C 1995 Studying nomads: an autobiographical reflection Nomadic Peoples 36/37 157-66

Scoones I ed 1995a Living with uncertainty: new directions in pastoral development in Africa Intermediate Technology Publications, Exeter

Scoones I 1995b New directions in pastoral development in Africa in Scoones I ed Living with uncertainty: new directions in pastoral development in Africa Intermediate Technology Publications, Exeter 1-36

Stenning D J 1959 Savanna nomads: a study of Wodaabe pastoral Fulani of western Bornu province, northern region, Nigeria Oxford University Press, London

Sutter J W 1987 Cattle and inequality: herd size differences and pastoral production among the Fulani of northeastern Senegal Africa 57 196-218

Taylor P J 1999 Places, spaces and Macy's: place-space tensions in the political geography of modernities Progress in Human Geography 23 7-26

Thébaud B 1995 Land tenure, environmental degradation and 
desertification in Africa: some thoughts based on the Sahelian example IIED Drylands Programme Issue Paper No. 57

Thébaud B and Batterbury S 2001 Sahel pastoralists: opportunism, struggle, conflict and negotiation a case study from Niger Global Environmental Change 11 69-78

Thomas D S G and Twyman C 2004 Good or bad rangeland? Hybrid knowledge, science, and local understandings of vegetation dynamics in the Kalahari Land Degradation \& Development 15 215-31

Touré O 1988 The pastoral environment of northern Senegal Review of African Political Economy 15 32-9

Touré O 1990 Where herders don't herd anymore: experience from the Ferlo, northern Senegal IIED Drylands Programme Issue Paper No. 22
Tuan Y E 1977 Space and place Arnold, London

Unwin T 2000 A waste of space? Towards a critique of the social production of space Transactions of the Institute of British Geographers NS 25 11-29

Warren A 1995 Changing understandings of African pastoralism and the nature of environmental paradigms Transactions of the Institute of British Geographers NS 20 193-203

Weicker M 1993 Nomades et sedentaires au Sénégal Série Etudes et Recherches No. 139-140 Enda-Editions, Dakar

Westoby M, Walker B and Noy-Meir I 1989 Opportunistic management for rangelands not at equilibrium Journal of Range Management 42 266-74

Widstrand C G 1975 The rational of nomad economy Ambio 4 146-53 
Copyright of Geographical Journal is the property of Blackwell Publishing Limited and its content may not be copied or emailed to multiple sites or posted to a listserv without the copyright holder's express written permission. However, users may print, download, or email articles for individual use. 